\title{
Application of the 18-Item Dementia Elderly Odayaka Scale in Japan: Evaluation before and after Intervention
}

\author{
Hiromi Tsujimura ${ }^{a}$ Makoto Osawa $^{b}$ Setsuko Makita ${ }^{b}$ \\ ${ }^{a}$ Graduate School of Health Sciences, Gunma University, Maebashi, Japan; ${ }^{b}$ Oido Clinic, Isesaki, Japan
}

\section{Keywords}

Assessment measures · Quality of life · Dementia care ·

Behavioral and psychological symptoms of dementia

\begin{abstract}
Introduction: We have developed the Dementia Elderly Odayaka Scale (DEOS) to evaluate psychosocial aspects in older people. The DEOS can be used to assess well-being, such as personhood and social interaction. Objective: The aim of this study was to apply the 18-item DEOS in participants with dementia and to examine the characteristics and usefulness of this scale. Methods: Facility staff provided care for the participants while taking into consideration each participant's individuality and strong points. The DEOS was applied at the beginning of the interventions and at 1 and 2 months after the start of the interventions. The changes in the participants' behaviors and their DEOS scores were then evaluated over time. Results: We examined 13 participants ( 2 men, 11 women) between the ages of 68 and 91 years. In $60 \%$ of the participants the DEOS score increased over time. When care interventions were tailored toward communication and leadership for the 2 men, according to each of their individualities, we observed increases in their scores for "social interaction" at 1 and 2 months thereafter. We also observed increases in the scores for "Expression of emotions"
\end{abstract}

karger@karger.com www.karger.com/dee

Karger $\frac{1}{\%}$

GOPEN ACCESS
(C) 2021 The Author(s)

Published by S. Karger AG, Basel

This article is licensed under the Creative Commons AttributionNonCommercial-NoDerivatives 4.0 International License (CC BY NC-ND) (http://www.karger.com/Services/OpenAccessLicense). Usage and distribution for commercial purposes as well as any distribution of modified material requires written permission. category in 2 of the 5 cases who received an aromatherapy massage. Discussion/Conclusion: The changes in the scores over time and the contents of the field notes were consistent with each other, suggesting that the DEOS can be used both to evaluate the effects of interventions and to plan care that takes advantage of each participant's positive aspects.

(c) 2021 The Author(s)

Published by S. Karger AG, Basel

\section{Introduction}

Japan has experienced an unprecedented increase in the aging of its society, and the prevalence of older people with dementia also continues to increase year by year. A report has estimated that the total number of older people in Japan will reach about 7 million in 2025 from 3.45 million in 2015 , with $20 \%$ of Japan's population being $>65$ years old [1]. Another report estimated that the total number of Japanese individuals with dementia was 2.8 million in 2010, but this number was expected to reach 4.7 million by 2025 , representing $13 \%$ of the Japanese population $>65$ years of age [2]. In 2012, the Japanese national government announced a "Five-Year Plan for Promotion of Measures against Dementia (Orange Plan)." This plan is aimed at the realization of a society in which 
Table 1. Research forms of the 18-item DEOS

1. Being able to interact with surrounding people

2. Being able to listen calmly to others

3. Being able to spend time with a friendly person

4. Being able to pay attention to others

5. Being able to love small children and animals

6. Being able to be kind to others

7. Being able to enjoy humor

8. Being able to enjoy an old tale

9. Being able to perform one's daily routine at one's own pace

10. Being able to express emotions (such as pleasure and suffering)

11. Being able to groom (makeup, hair style, clothing, belongings)

12. Being able to insist on one's will and wish

13. Being able to have pride as a human being

14. Being able to show joy with a smile

15. Being able to do something for others

16. Being able to be positive not negative

17. Being able to feel relaxed

18. Being able to work hard on what one likes

A total of 72 points represents the maximum sum of the 18 items. Each question is evaluated on a four-level Likert scale: "applicable" (4 points), "approximately applicable" (3 points), "not very applicable" (2 points), or "not applicable" (1 point). DEOS, Dementia Elderly Odayaka Scale.

persons with dementia can live with dignity in a pleasant and familiar environment that is to their liking for as long as possible [3]. As a result of the above-mentioned measures for dementia, the current direction of dementia care is to respect "personhood" and each individual's abilities $[4,5]$. Well-being and personhood have become major concepts in the care of people living with dementia [6-8]. A literature review reveals several scales for the assessment of dementia, including the evaluation of mental function, behavior disorders, and activities of daily living [9]. Quality of life (QoL) measures are often used when assessing positive aspects. Rabins and Kasper $[10,11]$ have developed the Alzheimer's Disease Health-Related Quality of Life scale, and Brod et al. [12] have developed the Dementia Quality of Life instrument to measure the QoL of dementia subjectively in an interview format. In addition, Terada et al. [13] developed a health-related QoL measure for Japanese participants. This scale can be used to assess both negative and positive aspects of dementia.

We developed the Dementia Elderly Odayaka Scale (DEOS) to evaluate the positive psychosocial aspects of older people with dementia living in facilities and at home [14-16]. We verified reliability and validity by statistical analysis. First, an exploratory factor analysis was conducted to investigate latent factors among the observed variables. We also examined the Cronbach alpha coeffi- cient, test-retest and interrater reliability, the validity of criteria related to the QoL scale, and so on. The 18-item DEOS (Table 1), which can be used to assess well-being, is classified into three domains: "Personhood," "Interaction with surroundings," and "Expression of emotions." Furthermore, since people with dementia reportedly have a better QoL when their caregivers experience lower levels of stress related to caregiving [17], the DEOS can also be indirectly used to evaluate the burden of care. The aim of this study was to apply the 18-item DEOS to older people with dementia and to examine its characteristics and usefulness. The results of the assessments were then used to provide suggestions on environment and care to promote well-being.

\section{Subjects and Methods}

We targeted 13 older people with dementia who were $>65$ years old (Table 2): 6 receiving outpatient long-term day care $(\mathrm{OP}), 3$ receiving home-visit nursing, 2 receiving home-visit rehabilitation, and 2 in a group home for persons with dementia. There were 2 men and 11 women, with mean (standard deviation) of 80.5 (6.5) years. Ten of the participants had been diagnosed as having Alzheimer's disease, 2 had been diagnosed as having dementia with Lewy bodies, and 1 had been diagnosed as having vascular dementia. The participants were classified according to the Clinical Dementia Rating, the care level of their long-term care insurance, and their independency level in daily 
Table 2. Demographic data, intervention method, and DEOS score after intervention

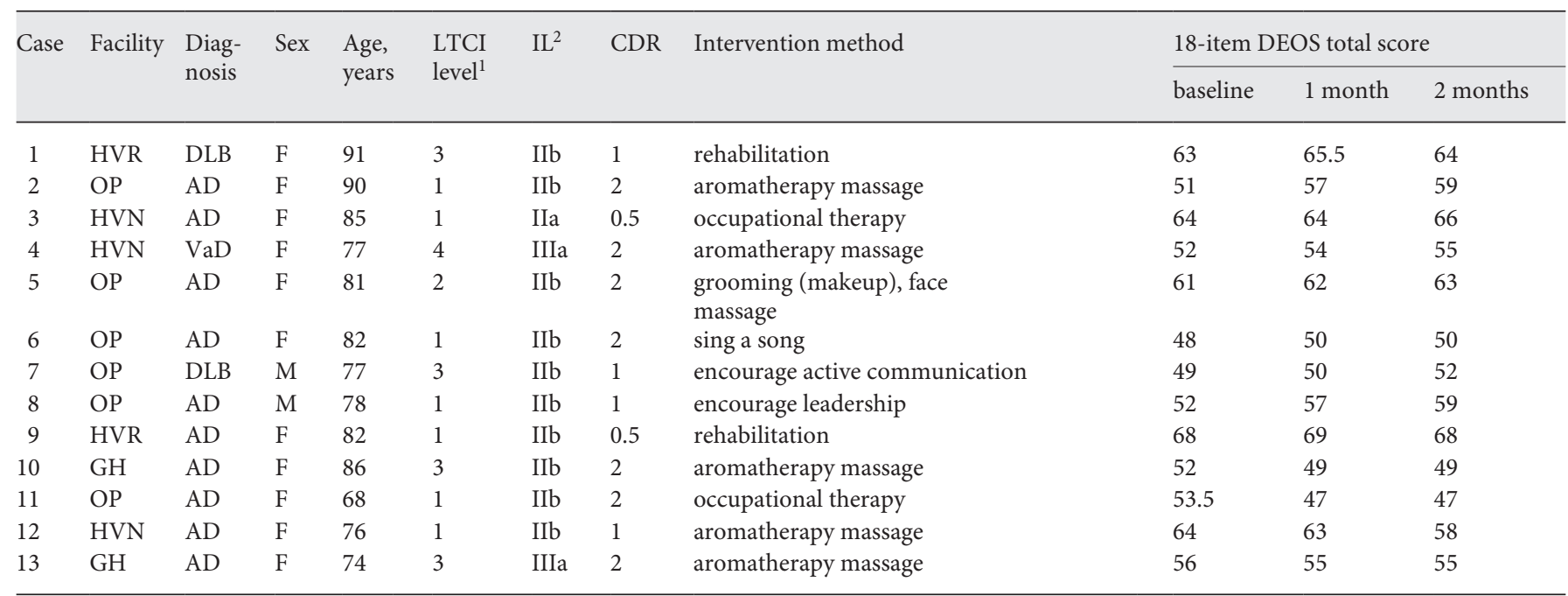

AD, Alzheimer's disease; CDR, Clinical Dementia Rating; DEOS, Dementia Elderly Odayaka Scale; DLB, dementia with Lewy bodies; GH, group home for persons with dementia; HVN, home-visit nursing; HVR, home-visit rehabilitation; IL, independency level; LTCI, long-term care insurance; OP, outpatient long-term day care; $\mathrm{VaD}$, vascular dementia. ${ }^{1}$ Level 1: low; level 5: high. ${ }^{2}$ IIa: almost independent; IIb: independence if someone is careful; IIIa: need some support; IIIb: need more support.

living for older people with dementia. The study exclusion criteria were a deterioration in the participant's health condition during the investigation, verbal incomprehension, and disapproval of the participant's family. The evaluators were nurses, care workers, and rehabilitation staff who worked at care facilities. Each evaluator was expected to have a good understanding of the daily life of the participant. The research period lasted from June 2017 to April 2018.

The research procedure was as follows: (1) Facility staff obtained consent from the participant's family prior to the enrollment of the participant in the survey. If there was no problem with daily conversation with the staff, the staff explained this study to the participant. (2) The staff determined the content of care after considering the participant's personality and strengths and consulting with the participant. The participant was given an oral explanation regarding their freedom to withdraw from the care at any time. (3) The staff provided care that respected the personality and strengths of the participant, observed the situation according to 18 -item DEOS, and recorded their conversation and behavioral changes in field notes. The same staff member was responsible for the longitudinal investigation in each case. (4) Similar to the content of the previous step, surveys were conducted 1 and 2 months later. (5) For each participant, the total scores of each survey and each category were calculated, and the change in the score was examined together with the descriptions in the field notes.

Operational definition of odayaka: In Japanese, the word odayaka generally means "mental stability." In the present paper, odayaka was additionally regarded as meaning the ability to interact with one's surroundings and to live in one's own manner despite a decline in cognitive function as a result of dementia.

\section{Results}

A Clinical Dementia Rating level of 2 and a long-term care insurance care level of 1 were most common (54\% of participants). The most common independency level was "independent if someone is careful" (69\%). The mean (standard deviation) of the total score was 56.4 (6.7) points at baseline, $57.1(7.1)$ points at 1 month, and 57.3 (6.7) points at 2 months, showing a slight increase over time. Approximately $60 \%$ of the total cases showed an increase in their score. The following describes the interventions that were used for cases 2,7 , and 8 , all of whom showed significant increases in their 18-item DEOS scores. These assessments allowed us to examine the characteristics and usefulness of the scale.

Case 2 is a participant who attends an OP program twice a week. She started attending OP after living with her daughter. She is a gentle woman who likes to take care of others. She recommends that people eat sweets, and so on, and advises anyone who is standing to sit and relax. She was worried about her family and dogs, had a strong desire to return home, and seemed restless. She often walked toward the entrance, especially in the afternoon, and seemed puzzled by her inability to spend time at her own home. Therefore, the staff provided her with a personalized aromatherapy massage once a day for about 15 min while talking with her to encourage relaxation. 


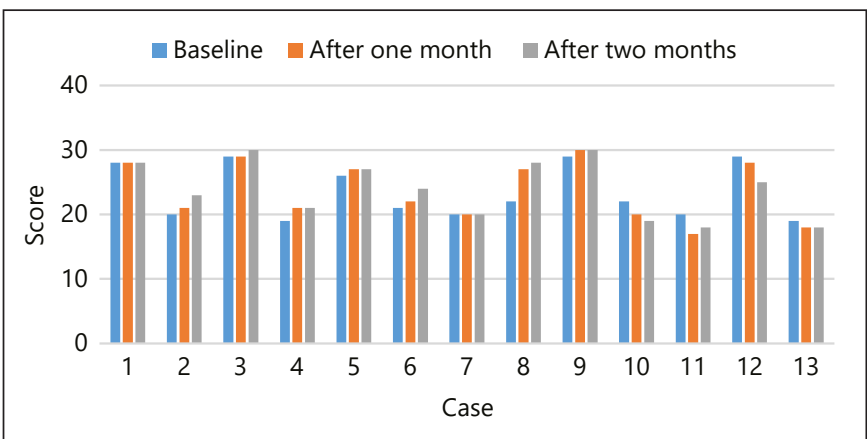

Fig. 1. Score changes over time for the "Personhood" category of the 18-item Dementia Elderly Odayaka Scale.

She was initially uncomfortable and often talked about her war experience, but after 1 month she began to mention her war experience less frequently, and by 2 months she was able to relax completely while receiving an aromatherapy massage. She had fewer attempts to leave the facility and was able to sit for longer periods. Her scores for seven items (questions 3, 7, 8, 10,12, 13, and 17) and for the "Personhood" and "Expression of emotions" categories all increased over time (Fig. 1,2).

Case 7 is a participant who attends OP three times a week while living with his wife. He could not understand the staff's explanations and was unable to participate in activities or to play games well. Since he was not very communicative, the staff used an approach that would encourage communication. Specifically, the staff helped him to sit close to people he likes so that he could talk with others. When he was sitting alone, the staff would take the time to talk with him. Through these efforts, he became more social and more active over time, according to the field notes. His scores for three items (questions 1, 6, and $10)$ and for the "Expression of emotions" and "Interaction with surroundings" categories increased over time (Fig. 2, 3).

Case 8 is a participant who attends OP four times a week while living with his wife. He was often angry and loud when events or specific times did not go as he expected. He had previously been a regional leader, so the staff took an approach that took advantage of his leadership role, such as providing him with a scheduled day. Specifically, they asked him for his opinion as a leader, and when he came to the facility every morning, the staff would say, "We expect you to be a leader again today." The staff also expressed their appreciation for his role as a leader. His scores for eight items (questions 4, 8, 9, 12, $13,14,16$, and 18) and for the "Personhood" and "Inter-

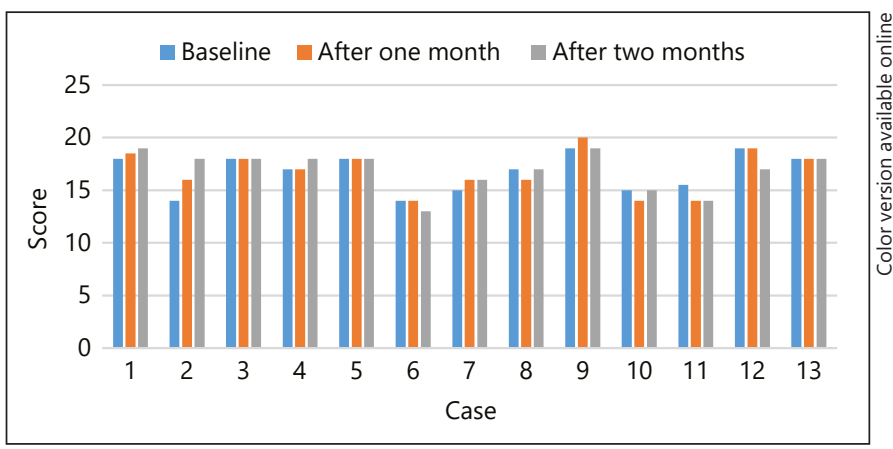

Fig. 2. Score changes over time for the "Expression of emotions" category of the 18-item Dementia Elderly Odayaka Scale.

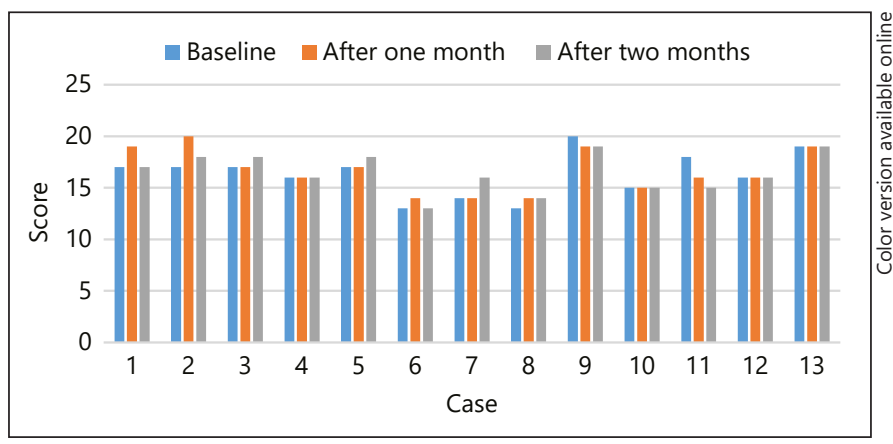

Fig. 3. Score changes over time for the "Interaction with surroundings" category of the 18-item Dementia Elderly Odayaka Scale.

action with surroundings" categories increased over time (Fig. 1, 3).

In this study, 4 of the 13 cases received rehabilitation interventions. Except for case 3, the total score either decreased (case 11) or fluctuated up and down (cases 1 and 9, shown in Table 2). The score for the "Expression of emotions" category of the 5 participants who received aromatherapy massages increased (cases 2 and 4), did not change (case 13), fluctuated up and down (case 10), or decreased (case 12) (Fig. 2).

\section{Discussion}

In case 2, the staff provided a personalized aromatherapy massage while talking to the participant, giving her the opportunity to express her emotions and to relax. In addition, the relaxed state may have helped her to talk about pleasurable memories rather than her war experi- 
ence. Previous studies have reported that aromatherapy can alleviate agitation and depressive mood [18-20] and can improve the cognitive function of people with dementia [21]. The above-described intervention was thought to have been linked to the increase in the participant's scores for questions $3,8,10,12$, and 17 and for the "Expression of emotions" and "Personhood" categories.

In case 7, we confirmed that the scores for "Being able to interact with surrounding people," "Being able to be kind to others," and "Being able to express emotions (such as pleasure and suffering)" had increased, and these improvements were thought to have been linked to the enhancement of social exchange through the staff's preparation of a favorable environment for communication. This intervention was thought to have been linked to the increase in the score for the "Interaction with surroundings" category.

In case 8 , the staff took the participant's past jobs and roles into consideration and provided care that leveraged his strengths and personhood. The "encourage leadership" intervention resulted in the largest increases in the scores for 8 of the 18 items over a 2-month period. Many items that can be evaluated using the DEOS are useful for developing care strategies that utilize a participant's individuality and strengths, and the effects of such care interventions can then be visualized by re-administering the scale. The above-mentioned intervention for case 8 was thought to have been linked to the increase in the scores for the "Personhood" and "Interaction with surroundings" categories. Encouraging leadership is crucial for enhancing person-centered care for people with dementia $[22,23]$.

Regarding rehabilitation interventions, the purpose of rehabilitation is to improve and maintain physical functions. Since the DEOS is a scale for evaluating psychosocial aspects, the rehabilitation interventions did not appear to have any effect on the DEOS results. For the participants who received an aromatherapy massage, the DEOS scores increased in 2 of the 5 cases, while the score remained unchanged in 1 case. Although a relationship between aromatherapy massage and emotional expression was suggested, further investigation using more cases will be needed in the future. While care interventions resulted in only a few increases in DEOS scores in the present study, further assessments based on treatment strategies, physical conditions, and mental conditions are needed. It was difficult to evaluate the effect of intervention due to changes in the physical and mental state of the participants because this study was conducted over a
2 -month period. DEOS is a scale developed in Japan, but it can be used overseas, so we would like to conduct a survey targeting foreigners in the future.

\section{Conclusion}

The changes in DEOS scores over time and the contents of the field notes were consistent with each other, and the DEOS is useful for both evaluating the effects of interventions and as a scale for planning care that takes advantage of the participant's positive qualities.

\section{Acknowledgment}

We would like to express our gratitude to everyone who cooperated with this research, including the participants, their family members, and the facility staff.

\section{Statement of Ethics}

The facility administrators encrypted the names of the participants and the evaluators and managed them in a ledger. We took considerations so that the researchers would not have direct access to personal information. Guardians of participants (their families) gave their written informed consent. The participants were given an oral explanation regarding their freedom to withdraw from the care at any time. This study was approved by Gunma University Ethical Review Board for Medical Research Involving Human Subjects (No. 2016-034).

\section{Conflict of Interest Statement}

The authors have no conflicts of interest to declare.

\section{Funding Sources}

This study received a Grant-in-Aid for Scientific Research (C) (15K11748) of the Japan Society for the Promotion of Science.

\section{Author Contributions}

H. Tsujimura contributed to the conception and design of this study and the analysis/interpretation of the data. M. Osawa contributed to the analysis/interpretation of the data. H. Tsujimura and S. Makita collected the data.
Tsujimura/Osawa/Makita 


\section{References}

1 Ministry of Health, Labour, and Welfare. Tokyo: Estimation of the future of the elderly with dementia. Available from: www.mhlw. go.jp/content/000524702.pdf [cited January $21,2020]$.

2 Ministry of Health, Labour, and Welfare. Emergency Project for Improvement of Medical Care and Quality of Life for People with Dementia (January 31, 2017).

3 National Center for Geriatrics and Gerontology. Dementia Prevention and Care in Japan. Available from: www.ncgg.go.jp/topics/dementia/documents/Session0-7TadayukiMIZUTANI.pdf [cited January 31, 2020]

4 Kitwood T. Dementia reconsidered: The person comes first. Berkshire: Open University Press; 1997. p. 1-176.

5 Ninchisho kaigo kenkyu kenshu Tokyo senta, editor. Ninchisho no hito no tame no keamanejimento senta-hoshiki no tukaikata ikashikata. Tokyo: Chuuo Hoki Shuppan; 2006. p. 16-45. Japanese.

6 Kitwood T, Bredin K. Towards a theory of dementia care: personhood and well-being. Ageing Soc. 1992;12(3):269-87.

7 Jenkins D, Price B. Dementia and personhood: a focus for care? J Adv Nurs. $1996 \mathrm{Jul}$ 24(1):84-90.

8 Oppikofer S, Albrecht K, Schelling HR, Wettstein A. Effects of social support on well-being of demented nursing home residents. The Käferberg Visitation Study. Z Gerontol Geriatr. 2002 Feb;35(1):39-48. German.
9 Imai Y, Kitamura S. Chihousei roujin no QOL to kazoku. Seishin Shinkeigaku Zasshi. 2000; 11:498. Japanese.

10 Rabins PV, Kasper JD. Measuring quality of life in dementia: conceptual and practical issues. Alzheimer Dis Assoc Disord. 1997; 11(Suppl 6):100-4.

11 Rabins PV, Kasper JD, Kleinman L, Black BS, Patrick DL. Concepts and methods in the development of the ADRQL: an instrument for assessing health-related quality of life in persons with Alzheimer's disease. J Ment Health Aging. 1999;5:33-48.

12 Brod M, Stewart AL, Sands L, Walton P. Conceptualization and measurement of quality of life in dementia: the dementia quality of life instrument (DQoL). Gerontologist. $1999 \mathrm{Feb}$; 39(1):25-35.

13 Terada S, Ishizu H, Fujisawa Y, Fujita D, Yokota O, Nakashima H, et al. Development and evaluation of a health-related quality of life questionnaire for the elderly with dementia in Japan. Int J Geriatr Psychiatry. 2002 Sep; 17(9):851-8.

14 Tsujimura H, Iwanaga K, Sato Y. Application of 18-item DEOS for dementia elderly people living at home and its reliability and validity. Kitakanto Med J. 2017 Aug;67(3):191-202.

15 Tsujimura H, Koizumi M. Application of 18 items DEOS for elderly people with dementia at facilities. J Jpn Soc Nurs Res. 2016 Sep; 39(4):89-96.

16 Tsujimura H, Koizumi M. Development of ODAYAKA (Serenity) Scale for Elderly Persons with Dementia. Kitakanto Med J. 2010 May;60(2):119-34.
17 Orgeta V, Orrell M, Hounsome B, Woods B; REMCARE team. Self and carer perspectives of quality of life in dementia using the QoLAD. Int J Geriatr Psychiatry. 2015 Jan;30(1): 97-104.

18 Yang YP, Wang CJ, Wang JJ. Effect of aromatherapy massage on agitation and depressive mood in individuals with dementia. J Gerontol Nurs. 2016 Sep;42(9):38-46.

19 Fujii M, Hatakeyama R, Fukuoka Y, Yamamoto T, Sasaki R, Moriya M, et al. Lavender aroma therapy for behavioral and psychological symptoms in dementia patients. Geriatr Gerontol Int. 2008 Jun;8(2):136-8.

20 Yang YP, Lee FP, Chao HC, Hsu FY, Wang JJ. Comparing the Effects of Cognitive Stimulation, Reminiscence, and Aroma-Massage on Agitation and Depressive Mood in People With Dementia. J Am Med Dir Assoc. 2016 Aug;17(8):719-24.

21 Jimbo D, Kimura Y, Taniguchi M, Inoue M, Urakami K. Effect of aromatherapy on patients with Alzheimer's disease. Psychogeriatrics. 2009 Dec;9(4):173-9.

22 Quasdorf T, Bartholomeyczik S. Influence of leadership on implementing Dementia Care Mapping: A multiple case study. Dementia. 2019 Aug;18(6):1976-93.

23 Rokstad AM, Vatne S, Engedal K, Selbæk G. The role of leadership in the implementation of person-centred care using Dementia Care Mapping: a study in three nursing homes. Nurs Manag. 2015 Jan;23(1):15-26. 